\title{
Modern approaches to adaptive tillage complexes in crop rotation and intensive land use in the Middle Urals
}

\author{
Y.N. Zybarev ${ }^{1}$, and D.S. Fomin ${ }^{1,2, *}$ \\ ${ }^{1}$ Perm State Agro-Technological University named after Academician D.N. Pryanishnikov, 23, \\ Petropavlovskaia St., 614990 Perm, Russia \\ ${ }^{2}$ Perm Agricultural Research Institute Branch of Perm Federal Research Center of Russian Academy \\ of Science, 12 Cultury St., Permskii Krai, 614532 Lobanovo, Russia
}

\begin{abstract}
The article presents the results of many years of research on soil treatment systems and techniques. It is established that for the conditions of the Perm region on sod-podzolic loamy soils, the most optimal system of basic treatment and reception is: 1. in grain-grass crop rotations with clean and occupied pairs, when applying medium and high doses of mineral and organic fertilizers, disk, minimum and plow-disk processing systems are most effective, ensuring the level of productivity of crop rotations is not lower than during annual plowing. At the same time, the humus content does not decrease, and the cost of soil processing is reduced by $20-35 \%$. To obtain maximum productivity in grain-grass crop rotations, multi-depth processing is promising, in which the costs are at the same level as the costs of ordinary processing, including annual plowing to a depth of $22-24 \mathrm{~cm} .2$. in grain-steam crop rotations, when applying medium and high doses of fertilizers, the most perspective processing is that which includes ploughing by $40 \mathrm{~cm}$ per pair, disking by $14 \mathrm{~cm}$ and ploughing by $20 \mathrm{~cm}$ for spring crops. Carrying out soil ploughing to a depth of $20 \mathrm{~cm}$ with SibIME stands instead of annual plowing is more effective, since this processing does not reduce the humus content, reduces the cost of processing by $17.8 \%$ and the yield of grain crops is not lower than with plow processing.
\end{abstract}

\section{Introduction}

In modern economic conditions, resource conservation is the most important direction in agriculture, which reduces the growth of irreplaceable energy costs (chemical ameliorants, mineral fertilizers, pesticides, fuel, electricity, and mechanization tools) in the structure of grain cost.

The transition to resource-saving technologies first of all must meet the requirements of environmental agriculture, which provide with the rational use of natural and anthropogenic resources, the development of energy-efficient techniques and technologies.

\footnotetext{
*Corresponding author: pniish@ rambler.ru
} 
Technology of cultivation of agricultural crops, the most energy-intensive process is soil processing, which takes more than $50 \%$ of energy costs.

Therefore, the technology of cultivation of any agricultural crop should be based on a resource-saving, soil-protective, adapted to the local conditions of the territorial structure of the landscape system of soil processing.

Modern adaptive intensification in the cultivation of field agrophytocenoses in the Middle Urals strongly depends on the fertility of arable soils. One of the components is the agrophysical state, which eventually affects the speed and rhythm of the passage and accumulation of soil nutrients, energy, and the ability to maintain a relatively high dynamic constancy of the composition and features of its internal environment [1-6].

The most important General agrophysical indicators are the density of addition, the density of the solid phase, which directly depend on the mineralogical composition of the soil-forming rock, the size of soil parts, the content of organic substance, the structural state and sponginess.

In field studies conducted from 1983 to 2016 on the experimental field of the Perm state agrarian and technological university, we tested and generalized modern approaches to soil processing in crop rotation and intensive land use, methodically and technologically developed models of formation and determination of agrophysical parameters of sodpodzolic soil fertility in different agricultural lands and crop rotations. It can be stated that with minimal, disk and reduced soil processing systems, the humus content does not decrease. On the contrary, disk and minimum soil processing provide a tendency to increase the humus content by $0.05-0.1 \%$, or by 1.6-3.1 tonn per hectare. The humus content does not decrease even with reduced soil processing. Thus, during annual plowing, regardless of its depth, even when applying high doses of dung and with presence of perennial grasses in crop rotations, the humus content decreases due to the intensive mineralization of all soil organic substances.

When soil processing is minimized, the amount of humus does not decrease. At the same time, a slight increase in the humus content is observed for disk and minimal soil processing.

In crop rotations with occupied steam and average doses of dung, the decrease in humus content during plow soil processing is more significant than in crop rotations with pure steam and high doses of dung. The average decrease in the amount of humus in crop rotations under the conventional processing system was $0.3 \%$ or 9.4 tonn per hectare (see table 44). There is no decrease in the amount of humus or it was insignificant with minimal disk and plow-disk soil processing systems. Consequently, both crop rotations with clean and occupied pairs show general regularities in the humus balance.

Purpose and methodology of research. The purpose of our research was a comparative study of the methods of basic soil processing on the weediness and productivity of crops in crop rotations.

\section{Materials and methods}

The research was conducted from 1983 to 2016 in the experimental fields of the Perm state agrarian and technological university. The soil of the experimental plots is sod-podzolic heavy loam.

The Department of General agriculture and plant protection of Perm state agrarian and technological university conducted field tests of the effectiveness of chisel, flat-cut, nondump stands SIBIME and ripper PRS-2.5, disk and plows with cut-out bodies of soil processing systems at different depths with it's constant use and in alternations over the years. In the grain-steam crop rotation, deployed in time, the Finch and steam main processing is carried out in different ways and at different depths. Scheme of experiment 2 
(Perm SATU): 1-Plowing to a depth of 20-22 cm; 2-Chiseling 16-18 cm; 3-Alternation of chiseling and plowing; 4 - Loosening (PRS - 2.5) by $30 \mathrm{~cm} ; 5$ - Plowing $20 \mathrm{~cm}$, loosening $30 \mathrm{~cm}$, plowing $30 \mathrm{~cm}$, loosening $20 \mathrm{~cm} ; 6$ - Plowing $20 \mathrm{~cm}$, loosening in pairs $40 \mathrm{~cm}$, loosening $20 \mathrm{~cm}$, disking at $12-14 \mathrm{~cm} ; 7$ - Subsurface loosening; 8 SibIME $30 \mathrm{~cm} ; 9$ Subsurface loosening; 10 - SibIME $20 \mathrm{~cm} ; 11$ - Disking 12 - $14 \mathrm{~cm} ; 12$ - Alternating disking $12-14 \mathrm{~cm}$ and a loosening $20 \mathrm{~cm} ; 13$ - Plowing by plows with cut-out bodies; 14 Flat- loosening; 15.Anti-erosion cultivator- 3,8 $14-18 \mathrm{~cm}$.

Agricultural technology in the experiment is generally accepted for field crops in the Perm region. Soil processing consisted of: a fall processing system that included postharvest husking (disking) and main processing in three to four weeks. In pure pairs, disking was performed in autumn or spring and the main processing was performed in late May or early June. Fall soil processing according to the scheme of experiments, early spring harrowing and pre-sowing cultivation in an aggregate with harrowing in two tracks to a depth of 8-10 cm. Fertilizers are applied for pre-sowing cultivation, forms of fertilizers ammonium nitrate, superphosphate and potassium chloride at the rate of N60P60K60. Sowing was performed within 24 hours after pre-sowing cultivation by $3-4 \mathrm{~cm}$ with a grain seeder-3.6 in an ordinary way. Care included herbicide treatment during the tillering phase. Harvesting was performed during the full ripeness phase of the self-propelled combine harvesters "Niva". During the years of research, meteorological conditions were not constant.

In the phase of grain crops entering the tube and before harvesting, the weeding of crops was taken into account.

\section{Results and discussion}

Soil processing is the basis of any technology for cultivating agricultural crops and the most important means of regulating water-air, heat and nutrient regimes, as well as controlling weeds, pests, and pathogens.

The traditional agrotechnical system of crop cultivation is based on dump soil processing, taking into account the soil and climatic conditions of the Urals, characterized by excessive moisture, insufficient heat-provided agrophysical features, and a shallow arable horizon.

However, along with its positive qualities, it has many disadvantages: it forms a "plow sole" - a water-permeable sealed layer, accelerates the mineralization of humus due to excessive aeration of the soil, and increases the intensity of erosion processes.

The high energy costs of the main processing system, based on annual plowing, do not allow it to be performed in optimal agrotechnical terms. As a result, plowing moves to a later date or to the spring period - "spring plowing", which leads to a deterioration of plant growth and development conditions due to late sowing dates and the formation of an incomplete and late harvest.

Experience of scientific institutions and best practices of farms shows that with the arrival of new agricultural tools, non-tilling soil processing is not inferior to traditional (dump plowing), and often exceeds it. The use of non-dump treatment on eroded and erosive-dangerous slope soils is especially relevant.

Use of flat-cut processing (on sloping soils), as research results show, with the same crop yield, reduces soil washout with meltwater in spring by $20 \%$.

The non-dump processing is less energy-intensive, which is an important argument in its favor when fuel prices are constantly rising. Inhibits the proliferation of non-dump soil processing increased weed infestation of crops after its application.

Therefore, one of the directions of resource saving during soil processing is the alternation of dump and non-dump processing in the field crop rotation. 
Combined soil processing system ensures the creation of a powerful root layer, regulates water-air and nutrient regimes in a favorable direction for plants, and clears the fields of weeds, pests and diseases.

The reserve of energy saving is minimal soil treatment, which also provides for reducing the depth of the processed layer and the number of technological operations. This system was developed at the Perm research Institute of agriculture, which allows to save energy when processing the soil, due to the alternation of dump and non-dump treatments using combined aggregates.

However, along with the positive aspects, it should be noted that even with periodic surface, flat-cut, and milling soil processes there was an increase in crop contamination and only in combination with the use of herbicides it was possible to reduce the number of weeds (table 1).

In agriculture, the weed component of agrophytocenoses has a contradictory impact on the ecology and economy of field crop cultivation. It is proved that weeds have a negative impact on the productivity of agricultural crops and are subject to destruction by various available methods (agrotechnical, chemical and biological). On the other hand, weeds leave behind plant remains and increase the stability of the ecosystem.

Adaptive landscape agriculture considers weed control from the point of view of environmental safety and maintains the number of weeds at an economically safe level.

Biotic and abiotic factors have different effects on the spread of weeds. The change in their number and weight depends on the crop, which itself is a strong ecological tool for regulating the number of weed components of agrophytocenosis.

The results of monitoring the weed component in the field seven-field paro-grain crop rotation showed that the mass of weeds is observed in spring wheat crops with meadow clover sowing exceeding the economic limit of harmfulness.

Further observation of the weed component shows that the number and mass of perennial weeds, mainly sow-thistle, increases in clover crops of one and two years of use. After harvesting the clover using mechanical method of control due to the main soil processing, the mass and number of weeds in barley crops is significantly reduced compared to previous crops. The main limiting factor in increasing the number of weeds is also the development of aboveground mass of barley and its high bushiness.

Observations of the weed component on three tabs of the experiment revealed a tendency to reduce the aboveground mass of weeds by the end of the third rotation of crop rotations.

The influence of soil processing systems on the weed component of agrophytocenoses was already evident by the end of the first rotation of crop rotations. Conventional soil processing contributes to a more rapid reduction of weed infestation of field crops.

When minimizing soil processing, there is a serious danger of increasing weed infestation of crops, which is why it is necessary to take into account the infestation of grain crops during the tillering and tube entering phases. The number of weeds and their shoots in these phases is always the maximum. By the period of grain ripening period, the number of weeds, as a rule, sharply decreases because of the death of their shoots, due to suppression by cultivated plants. So, table 1 illustrates the infestation of oat crops in the tillering phase at the end of crop rotations, and chemical weed control agents were not used in the crops. 
Table 1. Influence of the system (complex) of soil processing on oat infestation at the end of crop rotations, $\mathrm{PCs} / \mathrm{m}^{2}$

\begin{tabular}{|l|c|c|c|c|c|c|c|c|c|}
\hline \multirow{2}{*}{ System (complex) } & \multicolumn{2}{|c|}{ First tab } & \multicolumn{2}{c|}{ Second tab } & \multicolumn{2}{c|}{ Third tab } & \multicolumn{2}{c|}{ Average } \\
\cline { 2 - 10 } & total & $\begin{array}{c}\text { peren } \\
\text { nial }\end{array}$ & total & $\begin{array}{c}\text { perenni } \\
\text { al }\end{array}$ & total & perennial & total & $\begin{array}{c}\text { perenni } \\
\text { al }\end{array}$ \\
\hline \multicolumn{7}{|c|}{ Crop rotations with clean steam } \\
\hline Conventional & 52 & 21 & 426 & 4 & 293 & 1 & 257 & 2 \\
\hline Deep & 40 & 4 & 448 & 2 & 253 & 1 & 247 & 1 \\
\hline Multi-depth & 47 & 2 & 401 & 2 & 318 & 2 & 255 & 3 \\
\hline Reduced & 67 & 10 & 414 & 1 & 239 & 3 & 240 & 2 \\
\hline Minimal & 82 & 2 & 447 & 2 & 384 & 10 & 304 & 7 \\
\hline Plow-disc & 40 & 2 & 431 & 4 & 393 & 5 & 288 & 4 \\
\hline Disc & 55 & & 452 & 4 & 398 & 7 & 305 & 4 \\
\hline \multicolumn{7}{|c|}{ Crop rotation with a occupied steam } & & & \\
\hline Conventional & 53 & 3 & 406 & 1 & 240 & 2 & 233 & 2 \\
\hline Deep & 53 & 2 & 355 & - & 223 & 4 & 210 & 2 \\
\hline Multi-depth & 49 & 5 & 370 & - & 244 & 5 & 221 & 3 \\
\hline Reduced & 80 & 5 & 396 & 2 & 230 & 8 & 235 & 5 \\
\hline Minimal & 89 & 11 & 406 & - & 255 & 10 & 250 & 7 \\
\hline Plow-disc & 65 & 12 & 405 & 2 & 301 & 4 & 257 & 6 \\
\hline Disc & 76 & 7 & 349 & 1 & 344 & 13 & 256 & 7 \\
\hline
\end{tabular}

In the crop rotation with pure steam, the total weed infestation was stronger with minimal and reduced soil processing (table 2). the Weediness of the most harmful perennial weeds was five times higher with minimal soil processing than with conventional plowing.

In 1992, the overall weediness was very strong, but most of the weeds that were in the germination phase later died, and the weediness decreased to an average level by the time of harvesting. There were no regular differences in the number of weeds depending on the soil processing systems.

In 1993, the infestation of oat crops was stronger. At the same time, there were significantly more weeds in the minimum, disk and plow-disk soil processing systems than in conventional plowing. When the disk handling the excess was 105 weeds, with plow-disc - 100 and with a minimum of 91 weed. For these treatments, the infestation with perennial weeds was much stronger than for plowing.

On average, for three crop rotations, weeds were higher for disk and minimal processing. A slight decrease in infestation was observed with reduced and deep soil processing systems (table 4).

In crop rotations with occupied pairs, the total weediness was slightly lower on average over three years than in crop rotations with pure steam. At the same time, depending on the processing systems, similar patterns are noted as in crop rotations with pure steam.

Thus, minimization of soil processing in grain-grass crop rotations can lead to increased infestation, and therefore it is necessary to periodically use elective herbicides. It should be noted that the main processing applied in the non-chernozem zone of Russia, including disking (peeling) and plowing, does not ensure the purity of crops from weeds.

Material-technical and economic costs of tillage with the use of annual plowing in the cultivation of grain crops make up to $40 \%$ of the cost of production. That is why in modern agriculture, their reduction is an urgent task for farmers. The calculation of energy costs for various processing systems shows that the most significant reduction in costs is with minimal processing in the crop rotation system (a reduction of $35 \%$ ). 
By calculating the costs only for the main processing, it is possible to state that with minimal processing - they are half as much as with the traditional dump processing system.

Table 2. Energy costs of soil processing for rotation of crop rotations (1982-1993)

\begin{tabular}{|l|c|c|c|c|}
\hline \multirow{2}{*}{ System (complex) } & \multicolumn{2}{|c|}{$\begin{array}{c}\text { Crop rotations with pure steam, 80 } \\
\text { tons per hectare of steam dung }\end{array}$} & \multicolumn{2}{c|}{$\begin{array}{c}\text { Crop rotations with pure steam, 40 } \\
\text { tons per hectare of steam dung }\end{array}$} \\
\cline { 2 - 5 } & $\begin{array}{c}\text { Amount of } \\
\text { reference hectares } \\
*\end{array}$ & $\%$ & $\begin{array}{c}\text { Amout of } \\
\text { reference } \\
\text { hectares* }\end{array}$ & $\%$ \\
\hline Conventional & 10,81 & 100 & 10,54 & 100 \\
\hline Deep & 14,54 & 137 & 12,95 & 123 \\
\hline Multi-depth & 11,29 & 105 & 10,20 & 97 \\
\hline Reduced & 8,19 & 76 & 7,92 & 75 \\
\hline Minimal & 6,97 & 65 & 6,87 & 65 \\
\hline Plow-disc & 9,08 & 84 & 8,44 & 80 \\
\hline Disc & 7,68 & 71 & 8,46 & 72 \\
\hline
\end{tabular}

* a reference hectare is the amount of tractor work that corresponds to plowing a hectare under reference conditions (soil resistivity of $0.5 \mathrm{~kg} / \mathrm{cm}^{2}$ on grain stubble on medium loam with a humidity of $220-22 \%$, on a plot with the 800 meters of length of the machine's passage and a slope of up to $1^{\circ}$ ).

With reduced, disc-plow and disc soil processing systems, the cost of treatment was 16$29 \%$ less than with constant plowing. With different depths of soil cultivation, energy costs were at the same level as usual, but since this treatment resulted in a significant increase in crop productivity, it is the most promising for intensive farming. With deep processing, costs increased by $23-37 \%$. It did not provide an increase in productivity in comparison with the usual one, which includes plowing to an average depth of $22-24 \mathrm{~cm}$.

Energy costs are reduced and there is no loss of humus in the disk-plow system of soil processing. It should be noted that for the application of the studied soil processing systems in farms, it is not necessary to purchase new processing tools. For non-dump processing, serial plows with non-dump bodies, or with SIBIME stands are used, disc harrows BDT-3 and BDT-7 are available in most farms.

Since 1989, scientists of the Department of General agriculture and plant protection of Perm state agrarian and technological university have conducted field tests of the effectiveness of chisel, flat-cut, non-dump stands SIBIME and Ripper PRS-2.5, disk and plows with cut-out bodies of soil processing systems at different depths with their constant use and in alternations over the years.

In the first rotation, the contamination of barley was strong. At the same time, in comparison with plowing there were slightly more weeds when chiseling and alternating plowing and loosening. Reduced infestation was noted for non-dump loosening, as well as for plowing with a plow with cut-out bodies and alternating disking and loosening (table 3 ). Before harvesting the next crop in the crop rotation-oats, the infestation of young weeds was 2-3 PCs. $/ \mathrm{m}^{2}$, which was characterized as low infestation, after disking, their number reached $15 \mathrm{PCs} . / \mathrm{m}^{2}$ and during flat - cutting processing- $11 \mathrm{PCs} . / \mathrm{m}^{2}$.

The results of monitoring the infestation of crops in the second rotation of the crop rotation show that in the winter rye crop, the infestation was average. There were less weeds in the case of non-dump loosening to a depth of $30 \mathrm{~cm}$ and in the case of alternating disking and loosening by $20 \mathrm{~cm}$ in comparison with plowing. Increased infestation was observed when alternating treatments-plowing and chiseling and deep loosening of the soil with a plow-Ripper by $30 \mathrm{~cm}$, respectively, 72-73 PCs. $/ \mathrm{m}^{2}$ of weeds with $63 \mathrm{PCs} . / \mathrm{m}^{2}$ in 
the control. It is characteristic that during small soil processing - chiseling, disking and flatcutting - the blockage was not higher than during dump plowing.

Table 3. Influence of the main processing method on the infestation of crops in the crop rotation, $\mathrm{PCs} / \mathrm{m} 2$

\begin{tabular}{|c|c|c|c|c|c|c|c|}
\hline $\begin{array}{c}\text { System of soil } \\
\text { processin }\end{array}$ & $\begin{array}{c}\text { Barley } \\
1 \text { st } \\
\text { rotation }\end{array}$ & $\begin{array}{l}\text { Winter } \\
\text { rye } 2 \text { nd } \\
\text { rotation }\end{array}$ & $\begin{array}{l}\text { Barley } \\
\text { 2nd } \\
\text { rotation }\end{array}$ & $\begin{array}{l}\text { Oat } \\
\text { 2nd } \\
\text { rotation }\end{array}$ & $\begin{array}{l}\text { Winter } \\
\text { rye } \\
\text { 3rd } \\
\text { rotation }\end{array}$ & $\begin{array}{l}\text { Barley } \\
\text { 3rd } \\
\text { rotation }\end{array}$ & Average \\
\hline \begin{tabular}{|l|} 
Plowing to a depth \\
of $20-22 \mathrm{~cm}$
\end{tabular} & 260 & 63 & 144 & 107 & 5 & 322 & 150 \\
\hline Chiseling 16-18 cm & 275 & 59 & 167 & 127 & 6 & 316 & 158 \\
\hline 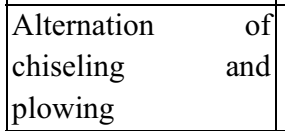 & 223 & 72 & 110 & 107 & 6 & 295 & 136 \\
\hline $\begin{array}{l}\text { Loosening } \\
(\mathrm{PRS}-2.5) \text { by } 30 \\
\mathrm{~cm}\end{array}$ & 237 & 73 & 144 & 136 & 3 & 324 & 153 \\
\hline $\begin{array}{|lcc|}\text { Plowing } & 20 & \mathrm{~cm}, \\
\text { loosening } & 30 & \mathrm{~cm}, \\
\text { plowing } & 30 & \mathrm{~cm}, \\
\text { loosening } & 20 \mathrm{~cm}\end{array}$ & 283 & 52 & 141 & 71 & 4 & 359 & 152 \\
\hline $\begin{array}{l}\text { Plowing } 20 \quad \mathrm{~cm}, \\
\text { loosening in } \\
40 \mathrm{~cm} \text {, loosening } 20 \\
\mathrm{~cm} \text {, disking at } 12- \\
14 \mathrm{~cm}\end{array}$ & 217 & 56 & 110 & 108 & 4 & 296 & 132 \\
\hline \begin{tabular}{|l} 
Non-dump \\
loosening; SibIME \\
$30 \mathrm{~cm}$
\end{tabular} & 193 & 38 & 140 & 83 & 2 & 364 & 134 \\
\hline $\begin{array}{l}\text { Non-dump } \\
\text { loosening; SibIME } \\
20 \mathrm{~cm}\end{array}$ & 208 & 62 & 119 & 115 & 3 & 375 & 147 \\
\hline Disking $12-14 \mathrm{~cm}$ & 242 & 59 & 121 & 124 & 9 & 399 & 159 \\
\hline $\begin{array}{l}\text { Alternating disking } \\
12-14 \mathrm{~cm} \text { and a } \\
\text { loosening } 20 \mathrm{~cm}\end{array}$ & 210 & 42 & 127 & 141 & 5 & 386 & 152 \\
\hline \begin{tabular}{|l|} 
Plowing by plows \\
with cut-out bodies
\end{tabular} & 212 & 58 & 114 & 110 & 6 & 359 & 143 \\
\hline \begin{tabular}{|l|} 
Flat- loosening \\
Anti-erosion \\
cultivator- $3,8 \quad 14-$ \\
$18 \mathrm{~cm}$
\end{tabular} & 236 & 65 & 134 & 219 & 7 & 399 & 177 \\
\hline
\end{tabular}

Later, in the second rotation of the crop rotation, it was found that with constant chisel processing, a number of weeds turned out to be more than it is with plowing, while all other soil processing systems provided a reduction in the number of weeds.

At the end of rotation in oat crops, the infestation of the soil during flat-cut processing strongly increased - up to $219 \mathrm{PCs} / \mathrm{m}^{2}$ of weeds, which is three times higher than the 
economic limit of harmfulness. During dump plowing, the infestation reached 107 PCs / $\mathrm{m}^{2}$, which also significantly exceeded the indicator. Infestation was also increased with constant chiseling, loosening of PRS-2,5, disking and alternating disking and loosening to a depth of $20 \mathrm{~cm}$. A decrease in infestation was observed only when the soil was loosened to a depth of $30 \mathrm{~cm}$.

Counting the number of weeds in the third rotation indicates that after clean steam, the winter rye infestation before harvesting was insignificant, but again there were more weeds during disking and processing with a flat-cutter cultivator, although in the steam field, these systems were carried out soil processes to a depth of $20 \mathrm{~cm}$.

In barley crops, it was very strong in all processing systems. Significantly increased the proportion of particularly dangerous perennial weeds - Thistle, sow-Thistle, field bindweed, betony. Of the juvenile weeds, white Marj, nettle, woodlouse, bedstraw tenacious, bindweeded buckwheat prevailed. The highest level of infestation was during continuous disking and flat-cutting processing - $399 \mathrm{PCs} / \mathrm{m}^{2}$, which is six times more than the economic limit of harmfulness.

The average number of weediness for three crop rotation rotations was the highest for flat-cut processing - $177 \mathrm{PCs} / \mathrm{m}^{2}$, and for plowing $-150 \mathrm{PCs} / \mathrm{m}^{2}$. A weediness during annual disking and chiseling of the soil was slightly more than for plowing. The decrease of infestation was observed when alternating plowing to a depth of $20 \mathrm{~cm}$, loosening in steam fields to a depth of 40 and $20 \mathrm{~cm}$ and disking for the last crop rotation, when alternating chiseling and plowing, and with constant non-dump loosening of SibIME to a depth of 30 $\mathrm{cm}$.

Thus, the most significant increase in crop infestation in the grain-steam crop rotation occurs when the soil is constantly treated with a flat-cut cultivator, a disc harrow, and a chisel cultivator. For other processing systems, the infestation is lower, or at the same level as for dump plowing.

Grain yields fluctuated significantly over the years, mainly due to weather conditions. It was highest for barley in the first rotation and winter rye in the third year. It was low for oats in the first and second rotation.

In the first rotation, a slight increase in the yield of barley was observed by alternating plowing by $20 \mathrm{~cm}$ and loosening under the barley by $30 \mathrm{~cm}$, which was 0.21 tonn per hectare in comparison with plowing. A decrease in yield was observed during flat-cutting and disking by 0.42 and 0.31 tonn per hectare respectively.

At the end of the first rotation, a severe drought was observed when growing oats. Under these conditions, a higher yield of oats was obtained by non-dump processing of PRS- 2.5 by $30 \mathrm{~cm}$ and SibIME stands by 30 and $20 \mathrm{~cm}$, as well as by plowing with a plow with cut-out bodies by $30 \mathrm{~cm}$ (table 4). At the same time, for small-scale processing -chiseling and disking - the yield was slightly lower than for plowing.

The yield of winter rye in the second rotation for non-dump loosening with SibIME stands to a depth of $20 \mathrm{~cm}$ was 0.43 tonn per hectare higher than for plowing. The productivity of plowing with a plow with cut-out bodies and alternating plowing, loosening by $20 \mathrm{~cm}$ and loosening by $40 \mathrm{~cm}$ in a pair was increased in comparison with the control. A decrease in grain yield was observed with constant chiseling and flat-cut processing (see table 4).

The yield of barley was slightly higher than it was for plowing with a plow with cut-out bodies. Productivity with constant disking was reduced. The productivity of oats was low due to the very strong lodging of oats and large losses during harvesting. A significant decrease in yield was observed with constant disking - by 0.6 tonn per hectare in comparison with plowing. The yield was reduced with constant chiseling and flat-cut soil processing. 
Table 4. Influence of the main soil processing system and reception on crop yield for two rotations of grain-steam crop rotation, tonn per hectare

\begin{tabular}{|c|c|c|c|c|c|c|c|c|}
\hline System of soil processing & 㐫 & 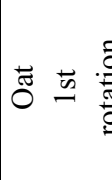 & 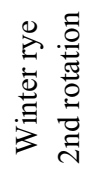 & 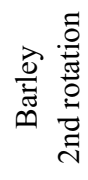 & 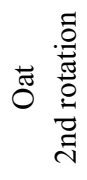 & 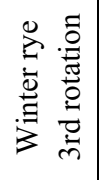 & 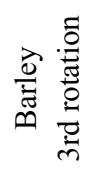 & $\begin{array}{l}\text { For } 7 \\
\text { years }\end{array}$ \\
\hline $\begin{array}{l}\text { Plowing to a depth of } 20-22 \\
\mathrm{~cm}\end{array}$ & 4,98 & 1,88 & 3,37 & 2,96 & 2,42 & 5,50 & 2,63 & 27,27 \\
\hline Chiseling 16-18 cm & 4,89 & 1,69 & 3,00 & 3,14 & 2,23 & 5,22 & 2,35 & 25,76 \\
\hline $\begin{array}{l}\text { Alternation of chiseling and } \\
\text { plowing }\end{array}$ & 4,71 & 1,71 & 3,44 & 2,94 & 2,47 & 5,32 & 2,75 & 26,81 \\
\hline $\begin{array}{l}\text { Loosening (PRS }-2.5) \text { by } \\
30 \mathrm{~cm}\end{array}$ & 5,01 & 2,06 & 3,35 & 2,96 & 2,38 & 5,57 & 2,63 & 27,14 \\
\hline $\begin{array}{l}\text { Plowing } 20 \mathrm{~cm} \text {, loosening } \\
30 \mathrm{~cm} \text {, plowing } 30 \mathrm{~cm}, \\
\text { loosening } 20 \mathrm{~cm}\end{array}$ & 5,19 & 1,89 & 3,12 & 3,09 & 2,29 & 5,15 & 2,98 & 26,92 \\
\hline $\begin{array}{l}\text { Plowing } 20 \mathrm{~cm} \text {, loosening } \\
\text { in pairs } 40 \mathrm{~cm} \text {, loosening } 20 \\
\mathrm{~cm} \text {, disking at } 12-14 \mathrm{~cm} \\
\end{array}$ & 5,16 & 1,86 & 3,64 & 2,94 & 2,33 & 5,40 & 2,89 & 27,96 \\
\hline $\begin{array}{|ll|}\text { Non-dump } & \text { loosening; } \\
\text { SibIME } 30 \mathrm{~cm} & \\
\end{array}$ & 4,84 & 2,09 & 3,56 & 3,00 & 2,32 & 5,50 & 2,57 & 27,31 \\
\hline $\begin{array}{l}\text { Non-dump loosening; } \\
\text { SibIME } 20 \mathrm{~cm}\end{array}$ & 4,85 & 2,06 & 3,80 & 2,95 & 2,37 & 5,51 & 2,56 & 27,48 \\
\hline Disking $12-14 \mathrm{~cm}$ & 4,67 & 1,79 & 3,26 & 2,69 & 1,82 & 4,95 & 2,45 & 24,51 \\
\hline \begin{tabular}{|l|} 
Alternating disking $12-14$ \\
$\mathrm{~cm}$ and a loosening $20 \mathrm{~cm}$
\end{tabular} & 4,81 & 1,77 & 3,48 & 2,94 & 2,34 & 5,09 & 2,52 & 25,79 \\
\hline \begin{tabular}{|l|} 
Plowing by plows with cut- \\
out bodies
\end{tabular} & 4,88 & 2,05 & 3,67 & 3,22 & 2,42 & 5,20 & 2,53 & 27,42 \\
\hline \begin{tabular}{|l|} 
Flat- loosening \\
Anti-erosion cultivator- 3,8 \\
$14-18 \mathrm{~cm}$
\end{tabular} & 4,56 & 1,89 & 3,06 & 2,80 & 2,24 & 4,76 & 2,49 & 24,40 \\
\hline
\end{tabular}

In the third rotation, the yield of winter rye $b$ was the highest for all the years of research. Higher yields were obtained by plowing to a depth of $20 \mathrm{~cm}$, loosening PRS-2.5 by $30 \mathrm{~cm}$, loosening SibIME by 20 and $30 \mathrm{~cm}$. These treatments produced 5.50-5.57 tonn per hectare of grain. A significant decrease in productivity in comparison with constant plowing was observed with flat - cut soil processes y during disking by 0.74 and 0.55 tonn per hectare, respectively. The yield was lower than for plowing when alternating plowing and loosening by 20 and $30 \mathrm{~cm}$, when chiseling and plowing with a plow with cut-out bodies. The yield of barley was increased by alternating plowing and loosening to a depth of 20 and $30 \mathrm{~cm}$. For all other processing systems, the differences with the control are insignificant.

For two rotations of the grain-steam crop rotation, the grain harvest with constant plowing with preliminary disking amounted to 27.27 tons. When alternating plowing by 20 $\mathrm{cm}$, loosening by $20 \mathrm{~cm}$ for spring crops and $40 \mathrm{~cm}$ in steam and disking, grain collection was higher by 0.69 tonn per hectare. With constant non-dump loosening of SibIME by 20 $\mathrm{cm}$, the grain harvest was slightly higher than for plowing. When the soil was loosened by PRS-2.5, as well as by SibIME stands at $30 \mathrm{~cm}$, the grain yield was at the same level as the harvest with constant plowing to a depth of $20 \mathrm{~cm}$. 
A significant decrease in grain collection was observed when the soil was treated with a flat cutter and with constant disking. Here was obtained less grain than with plowing by 2.87 and 2.76 tonn per hectare, respectively. A decrease in grain collection by 1.51 tonn per hectare was observed with constant chiseling and by 1.48 tonn per hectare with alternating disking and loosening by $20 \mathrm{~cm}$.

\section{Conclusions}

Thus, for the conditions of the Perm region on sod-podzolic loamy soils, the most optimal system of basic treatment and reception is:

1. in grain-grass crop rotations with clean and occupied steam when applying medium and high doses of mineral and organic fertilizers, disk, minimum and plow-disk processing systems are most effective. They ensuring the higher level of productivity of crop rotations than during annual plowing. At the same time, the humus content does not decrease, and the cost of soil processes is reduced by $20-35 \%$.

To obtain maximum productivity in grain-grass crop rotations, multi-depth processing, in which the costs are at the same level as the costs of conventional processing, (including annual plowing to a depth of $22-24 \mathrm{~cm}$ ) is promising.

2 . in grain-steam crop rotations, when applying medium and high doses of fertilizers, the most promising treatment is disking by $14 \mathrm{~cm}$ and loosening by $20 \mathrm{~cm}$ for spring crops including loosening by $40 \mathrm{~cm}$ per pair.

Carrying out soil loosening to a depth of $20 \mathrm{~cm}$ with SibIME stands instead of annual plowing is more effective, since this treatment does not reduce the humus content, does not decrease the yield of grain crops lower than with plow processing and reduces the cost of processing by $17.8 \%$

\section{References}

1. L.B. Nitchenko, V.A. Plotnikov, Bulletin of the Kursk State Agricultural Academy, 7, 33-38 (2018)

2. Yu.V. Vorontsova, Bulletin of the Kursk State Agricultural Academy, 5 17-20 (2011)

3. V.T. Lobkov, S.A. Plygun, RJOAS, 1, 3-6 (2012)

4. L.M. Kozlova, N.E. Rubtsova, N. Soboleva, Agrarnaya nauka Evro-Severo-Vostoka, 5(54), 56-62 (2016)

5. J.M. Baker, T.E. Ochsner, R.T. Venterea, T.J. Griffis, Agriculture, Ecosystems and Environment, 118, 1-5 (2007)

6. E.A. Krasnova, V.V. Rzaeva, Agrarian bulletin of the Urals, 5(184), 4-8 (2019) DOI: 10.32417/article_5d5151b13c3e81.50736248. 